\section{Submucosal hemorrhage in the descending duodenum: endoscopic findings of acute severe pancreatitis}

A 56-year-old man whose history was significant only for obesity (body mass index 34) presented with severe acute gallstone pancreatitis and cholangitis. His condition deteriorated, despite maximum supportive measures including intravenous antibiotics, and he soon required admission to intensive care. A noncontrast CT scan (because of renal failure) revealed marked peripancreatic fat stranding in keeping with acute pancreatitis. An emergency endoscopic retrograde cholangiopancreatography (ERCP) 36 hours after admission revealed severely edematous and hemorrhagic duodenal mucosa around the papilla, both above and below, over an $8-\mathrm{cm}$ extent on the medial wall with contact bleeding ( $\bullet$ Fig. 1). The ampulla was difficult to identify or view en face but was successfully cannulated and biliary sphincterotomy performed ( Fig. 2). The duct was swept, delivering sludge without discrete stone. A 7F, 7-cm double pigtail stent (ZSO-7-7; Cook Australia, Brown Plains, Brisbane, Queensland, Australia) was inserted to ensure continued adequate drainage given the severity of the mucosal edema ( Fig. 3). Rapid resolution of symptoms followed and the patient was discharged on day 23. ERCP 6 weeks later revealed multiple small common bile duct stones that had presumably passed in the interim. Cholecystectomy is planned.

Gastrointestinal ulceration can develop in up to $65 \%$ of patients with acute pancreatitis and prophylactic acid suppression therapy is likely to be beneficial in this patient group [1]. Submucosal hemorrhage is, however, likely to be a manifestation of severe necrotizing pancreatitis.

Endoscopy_UCTN_Code_CCL_1AB_2AZ_3AC

S. Alexander, M. J. Bourke, J. Co, S. J. Williams, A. Bailey

Department of Gastroenterology and Hepatology, Westmead Hospital, Sydney, Australia

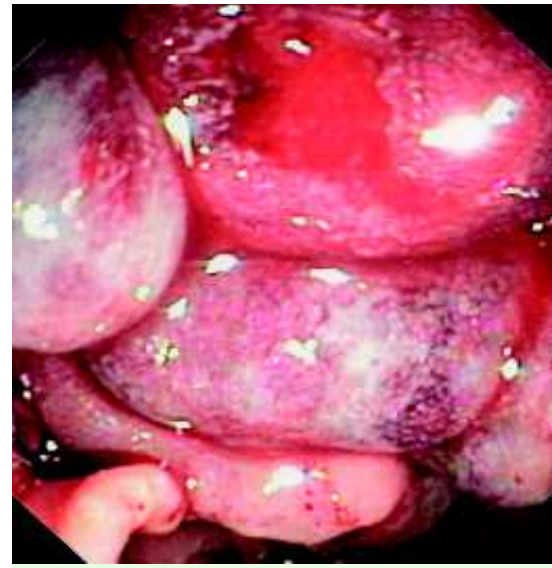

Fig. 1 Severe mucosal edema and hemorrhage.

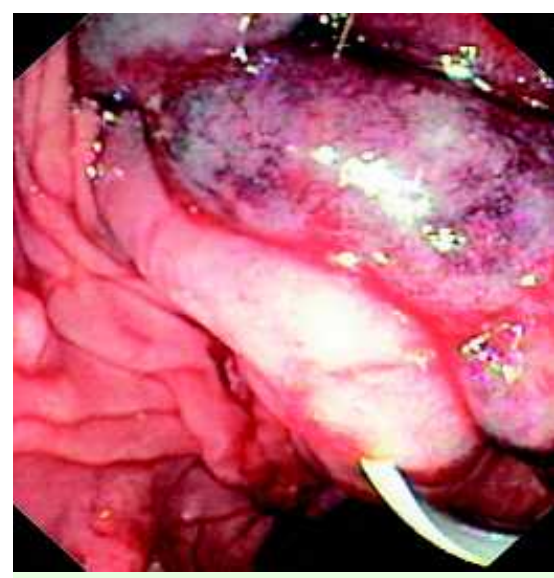

Fig. 2 Ampullary cannulation and biliary sphincterotomy.

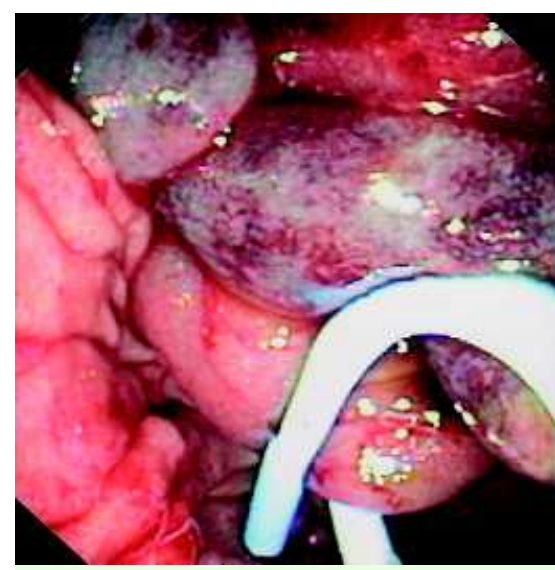

Fig. 3 Double pigtail stent for adequate drainage.
References

1 Chen TA, Lo GH, Lin CKet al. Acute pancreatitis-associated acute gastrointestinal mucosal lesions: incidence, characteristics, and clinical significance. J Clin Gastroenterol 2007; 41: 630-634

Bibliography

DOI 10.1055/s-2007-995545

Endoscopy 2008; 40: E188

(c) Georg Thieme Verlag KG Stuttgart · New York . ISSN 0013-726X

Corresponding author

M. J. Bourke MD

Endoscopy Unit

Westmead Hospital

Hawkesbury Rd

Westmead

NSW 2145

Australia

Fax: 61296335082

s_alexander36@hotmail.com 